\title{
A COMPUTER-ASSISTED VO CREATION FRAMEWORK
}

\author{
Luis M. Camarinha-Matos ${ }^{1,2}$, Ana Inês Oliveira ${ }^{2}$, \\ Roberto Ratti ${ }^{3}$, Damjan Demsar ${ }^{4}$, Fabiano Baldo ${ }^{5}$, Toni Jarimo ${ }^{6}$ \\ ${ }^{I}$ New University of Lisbon, PORTUGAL, cam@uninova.pt \\ ${ }^{2}$ UNINOVA, PORTUGAL, aio@uninova.pt \\ ${ }^{3}$ TXT Solutions, ITALY, Roberto.ratti@txt.it \\ ${ }^{4}$ Jozef Stefan Institute, SLOVENIA, damjan.demsar@ijs.si \\ ${ }^{5}$ Federal University of Santa Catarina, BRAZIL, baldo@gsigma.ufsc.br \\ ${ }^{6}$ VTT Technical Research Centre of Finland, FINLAND, toni.jarimo@vtt.fi
}

\begin{abstract}
Computer assistance in the process of creation of virtual organizations (VO) is an important condition for the possibility of having truly dynamic VOs, in response to collaboration opportunities in fast changing market contexts. A realistic approach to materialize agility in $V O$ creation is defined with the assumption of a VO Breeding Environment (VBE) that guarantees the preparedness of its members to quickly get engaged in collaboration processes. A discussion of the process and a set of key functionalities towards a VO creation framework are presented in this context. The approach, architecture, and first results with such tools are described and challenges for future research are identified.
\end{abstract}

\section{INTRODUCTION}

The concept of virtual organization (VO) appears as particularly well-suited to cope with very dynamic and turbulent market conditions. This is largely due to the possibility of rapidly forming a consortium triggered by a business opportunity and specially tailored to the requirements of that opportunity. Implicit in this idea is a notion of agility, allowing rapid adaptation to a changing environment. In the heart of this notion is the VO creation process.

Finding the right partners and establishing the necessary conditions for starting a collaboration process have however proved to be costly in terms of time and effort, and therefore an inhibitor of the aimed agility. First a VO planner might face lack of information about the profile and competences of potential partners. The actual capacities and willingness to get involved in a consortium are dynamic and might depend on a negotiation process. Second, collaboration might be hindered by mismatches due to different infrastructures used by different partners, different business cultures and methods of work, different expectations, lack of trust, etc. Overcoming these mismatches is time consuming and therefore an obstacle for rapid consortium formation. Third, the decision on which partner to select for each needed task depends not only on characteristics such as competencies, resources, etc, but also on past performance in collaborative processes, capability to work together with the other partners, and the preferences of the VO planner. 
It is therefore necessary to develop an approach and a supporting framework to facilitate the VO creation process in order to make it effective. This article describes the approach developed by the ECOLEAD project and introduces a set of developed tools to support various steps of the VO creation process.

\section{PREVIOUS APPROACHES}

The VO creation process has received considerable attention in past research work. However, most of the developments were aimed at designing a fully automated process and frequently based on a set of simplistic assumptions.

For example, a large number of works have been published on the application of multi-agent systems and market-oriented negotiation mechanisms for the VO formation. One early example can be found in [19], which assumes a virtual market place where enterprises, represented by agents, can meet each other and cooperate in order to achieve a common business goal. A similar work is found in [14] where a more detailed analysis of the problem of goal decomposition, leading to a hierarchy of VO goals, is done. The work described in [21] identifies the need for yellow pages agents that are responsible to accept messages for registering services. They also consider the notion of Local Area, a concept similar to the Local Spreading center first introduced by the HOLOS system [17, 18]. [11] elaborates further on the application of market-oriented principles, such as the general equilibrium in micro-economics. More recently, [12] describes a gametheoretic approach to support negotiation in VO formation. More recent works have attempted to progress with new negotiation protocols, auction mechanisms, distributed matching processes, learning, etc.

In order to improve the effectiveness of the contracting process and to dynamically form VOs, the need to develop forms of e-contracting has also been identified. Several significant characteristics for the e-contracting process can be found in [3]. Deontic logic [15] is used to describe contract models specifying obligations, permissions, and forbiddances for a specific business process which works in an extremely ideal process. Contracts in CrossFlow and E-ADOME projects describe the agreed workflow interfaces as activities and transitions, based on WfMC's WPDL (Workflow Process Definition Language).

Another line of work is the service-federation approach or implicit VO creation. companies (potential members of the virtual organization) are considered as "service providers", i.e. the potential collaborative behavior of each company is "materialized" by a set of services [1].

Other researchers put the emphasis on formulating the VO creation as an optimization problem. Several researchers present integer programming models where the objective is to minimize total costs which consist of production, operation, and transportation costs, for instance [8, 13, 22]. However, it has been recognized that VO creation is essentially a multi-criteria decision-making problem, including also soft factors such as corporate culture, personal preferences, and learning ability, which are not incorporated in pure cost models. Responding to this challenge, earlier literature presents some multi-criteria models, which however seem to lack one important issue, namely explicit modeling of inter-organizational correlations between partner candidates $[4,16,20]$.

For instance collaboration history, trust, and similarity of ICT infrastructure are criteria that need to be considered for a group of organizations rather than for a 
single organization. On the other hand, several other aspects, in addition to the preferences of the VO planner, are of a dynamic nature in the sense that they depend on the negotiations with potential partners.

\section{THE ECOLEAD FRAMEWORK}

As mentioned above, when the window of opportunity is short, in order to support the rapid formation of a VO it is necessary that enough information is available about potential partners and that they are ready and prepared to participate in such collaboration. This readiness includes common interoperable infrastructure, common operating rules, common cooperation agreement, and a base trust level among the organizations, among others. Therefore, the approach adopted in ECOLEAD considers that dynamic VOs are mostly created in the context a VO Breeding Environment (VBE). A VBE can be defined [2,5] as: an association of organizations and their related supporting institutions, adhering to a base long term cooperation agreement, and adoption of common operating principles and infrastructures, with the main goal of increasing both their chances and their preparedness towards collaboration in potential Virtual Organizations. Some of the main aims of the VBE include:

- Establish the base trust for organizations to collaborate in VOs.

- Reduce the cost/time to find suitable partners for configuration of the VOs.

- Assist with the creation, reaching agreements, and contract negotiation for establishment of VOs.

- Assist with the dynamic reconfiguration of the VOs, thus reducing the risk of losses due to some organization failures.

- Provide some commonality for interaction by offering: (i) Base ICT infrastructure (for collaboration), thus reducing the set up times during the $\mathrm{VO}$ formation; (ii) Cooperative business rules and common metrics to evaluate member's credibility and performance; (iii) Template contracts for involvement in VOs; (iv) Base ontology for the sector targeted by the VBE.

- In addition to the enterprises, a VBE might include other kinds of organizations (such as consulting/research institutes, sector-associations, governmental support organizations, etc.) and even free-lancer individual workers that represent a one-person small organization. A VO is a temporary organization triggered by a specific business / collaboration opportunity. Its partners are primarily selected from the VBE members. In case there is a lack of skills or capacity inside the VBE, organizations can be recruited from outside. For difficulties of preparedness, trust, etc, this last category will, of course, be the last resort.

When a contract for a new collaboration opportunity is already "guaranteed", the VO creation process can be illustrated by Fig. 1 [7]. The preparatory planning phase includes:

- Collaboration Opportunity Identification and Characterization: this step involves the identification and characterization of a new Collaboration Opportunity (CO) that will trigger the formation of a new VO. A collaboration opportunity might be external, originated by a customer and detected by a 
VBE member acting as a broker. Some opportunities might also be generated internally, as part of the development strategy of the VBE.

- Rough VO planning: determination of a rough structure of the potential VO, identifying the required competencies and capacities, as well as the organizational form of the VO and corresponding roles. At this stage it is important to define the partnership form which is typically regulated by contracts and cooperation agreements.

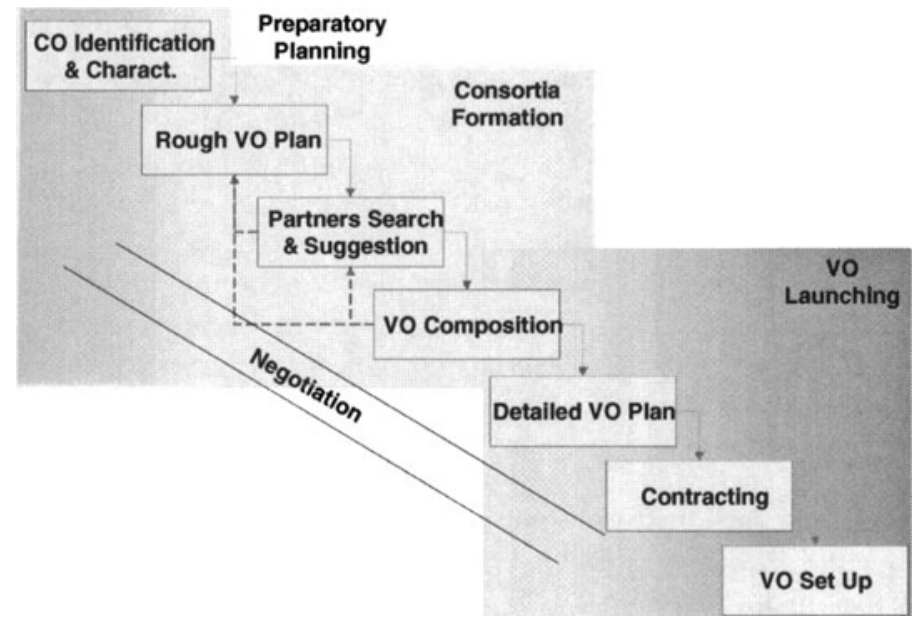

Figure 1 - VO creation process for acquired opportunity

The consortia formation phase departs from the previous characterization and rough planning and mainly includes:

- Partners search and suggestion: perhaps one of the most addressed topics in past research this step is devoted to the identification of potential partners, and their assessment and selection.

- Negotiation: is an iterative process to reach agreements and align needs with offers. It can be seen as complementary to the other steps in the process and runs in parallel with them as illustrated in Fig. 1.

- VO composition: in which the organizational structure and assignment of roles to VO members are made.

- The VO launching phase includes:

- Detailed VO planning: once partners have been selected and collaboration agreements are reached, this step addresses the refinement of the VO plan and its governance principles.

- Contracting: involves the final formulation and modeling of contracts and agreements as well as the contract signing process itself, before the VO can effectively be launched. In other words, this step is the conclusion of the negotiation process.

- VO set up: the last phase of the VO creation process, i.e. putting the VO into operation, is responsible for tasks such as configuration of the ICT infrastructure, instantiation and orchestration of the collaboration spaces, selection of relevant performance indicators to be used, setting up of the VO governance principles, assignment and set up of resources/activation of 
services, notification of the involved members, and manifestation of the new $\mathrm{VO}$ in the VBE.

In the business domain it is however very often necessary to consider two main phases, as shown in Fig. 2.

1. Quotation/bidding - when a collaboration opportunity is found it is necessary to prepare a bid/quotation in order to try to get a contract with the customer. For the preparation of this bid, it is necessary to make a rough plan of the foreseen $\mathrm{VO}$ and to also select the core partners. The bid is often prepared by this initial consortium. In case the bid is unsuccessful, the core consortium dissolves; otherwise we move to the next phase.

2. Final VO creation - In case the bid is successful, the VO's rough plan needs to be revised, based on the specific conditions of the contract with the customer, new additional partners might be necessary, and the VO will be finally detailed and launched.

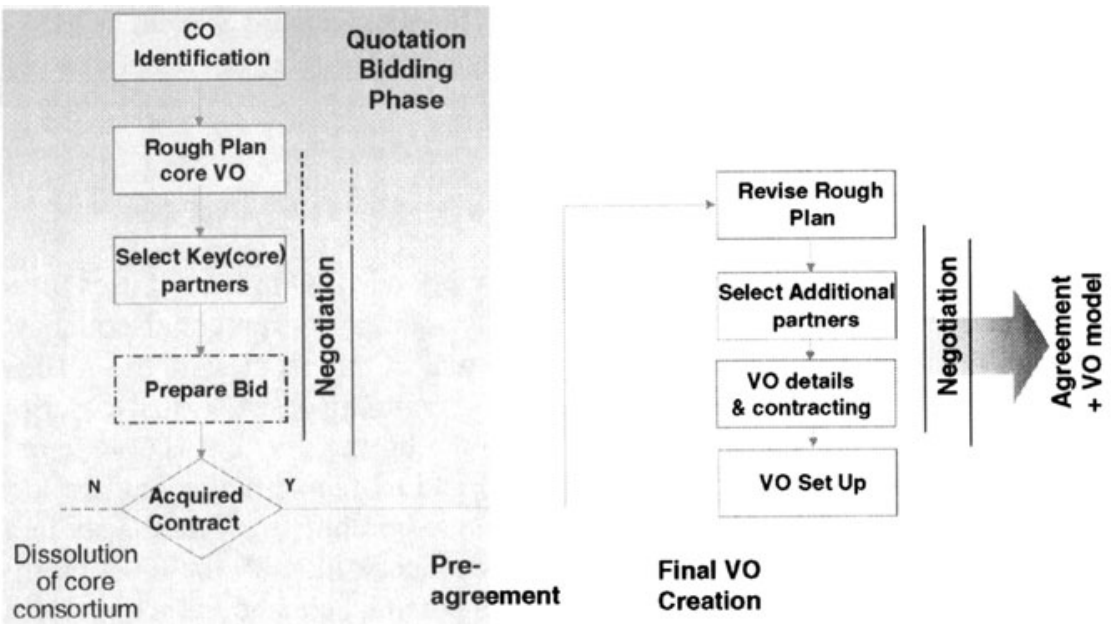

Figure 2 - VO creation process for quotation/bidding

Based on the process and requirements described above, and as a result of extensive interaction with industry end-users, the VO creation framework developed by the ECOLEAD consortium (by different partners, namely UNINOVA, TXT, JSI, UFSC, VTT, and ITESM) is focused on the following tools (Fig. 3):

a) Collaboration opportunity $(\mathrm{CO})$ finder,

b) $\mathrm{CO}$ characterization and $\mathrm{VO}$ rough planner,

c) Partners' search and suggestion, and

d) Agreement negotiation wizard, which are introduced in the next sections. 


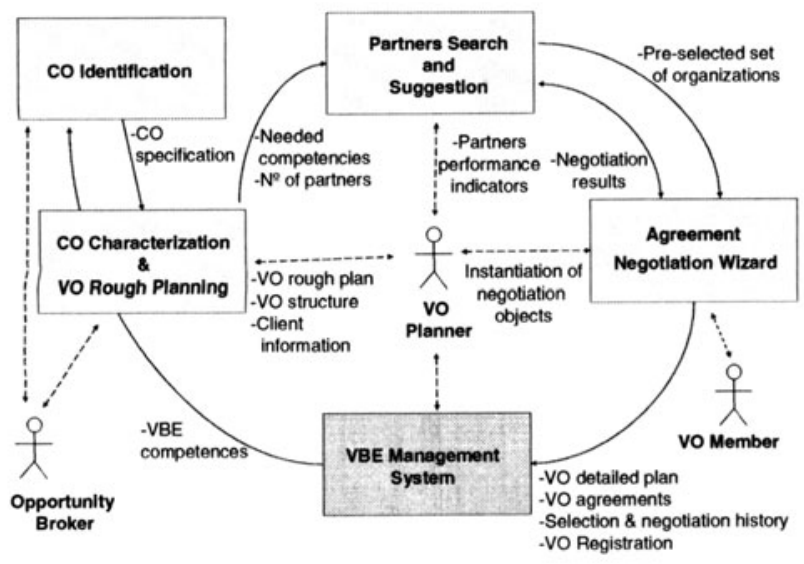

Figure 3 - VO creation support tools

These tools are supposed to interact with a VBE Management System (VMS) from where relevant data (e.g. profiles, competencies, historical data) about potential partners can be collected.

\section{COLLABORATION OPPORTUNITY IDENTIFICATION}

The coFinder tool is aimed at facilitating the work of a VO broker. It uses the same approach that is usually carried out manually: comparing potential collaboration opportunities (calls for tenders) with the actual competencies of the VBE. The matching in the coFinder tool is based on the comparison of textual descriptions of tenders and VBE competencies. Similar to the broker, the tool is able to browse public calls for tenders available on the Web and extract calls for tenders' descriptions from the HTML pages. coFinder is able to compute their similarity in order to estimate the interestingness of the calls for tenders, identify the most promising ones, and finally propose them to the broker as potential collaboration opportunities. The output of the system is a list of potential collaboration opportunities stored in an XML document.

The collaboration opportunity identification process comprises several steps:

1. First, the user provides information such as a list of tender servers that he intends to use for finding potential collaboration opportunities. In addition, for each server, the user must create a template that is used to identify tenders' descriptions inside the HTML pages. There are two possible ways of creating a template: semi-automatically, by comparing two existing calls for tenders on the server, or manually by editing the HTML code of an existing call for tenders. Another input needed is the competencies of the VBE.

2. After all this information is provided, the coFinder tool crawls all the specified servers and gathers calls for tenders' web pages. It is possible to schedule this process to retrieve new calls for tenders periodically.

3. The next step is parsing. The template previously built is used here to extract tenders' descriptions from their web pages. The information is then stored in a database using the CO XML schema. 
4. Once the calls for tenders' description has been extracted and structured, it is possible to identify potential collaboration opportunities by matching tenders' description with the available competencies (an example is shown in Fig. 4). The interestingness factor is computed for each tender. This measure is a weighted sum of the similarity between textual fields describing the call for tenders and textual fields describing VBE competencies.

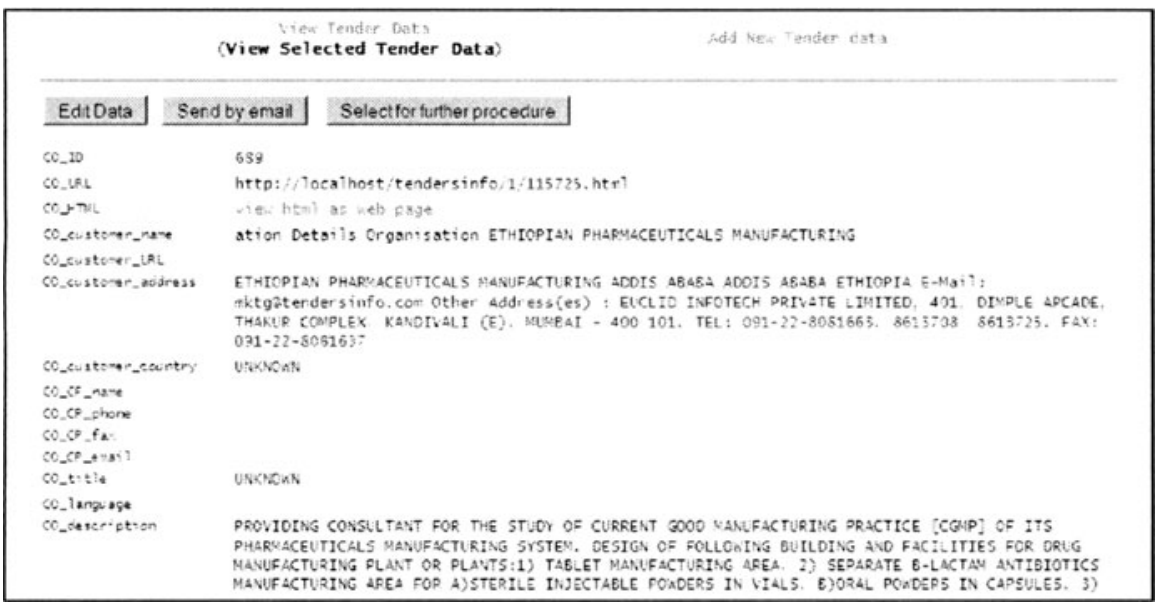

Figure 4 - Example of a $\mathrm{CO}$

To limit the number of potential collaboration opportunities, a threshold is used for the interestingness measure. The user, at the beginning of the process, sets this threshold. The VO broker will be notified by e-mail only about the potential collaboration opportunities that are above this threshold. It is also possible to browse and search through all the collected tender data, select the tenders suitable for VO creation, or just select the data to be sent by an e-mail to the VO broker. Since all needed data is not always available in the tender data supplied by the server, the system offers the possibility to include some data that the VO broker may collect using other methods (phone calls, email correspondence, etc.). Such data can be useful in further steps of VO creation.

\section{CO CHARACTERIZATION AND VO ROUGH PLANNING}

This section describes the second tool of the VO Creation framework, the CO Characterization and VO Rough Planning (COC-Plan) tool. Once a Collaboration Opportunity is identified, it should be better described and represented in a structured way in order to support the VO broker during the CO definition and characterization process. In this stage, the preparation of a detailed structure of the VO process is also needed. The objective of the module is twofold:

1. To characterize the $\mathrm{CO}$, by completing the $\mathrm{CO}$ description form initialized by the coFinder module. In particular, the $\mathrm{CO}$ description form is completed with the name of the VO broker, the needed competencies and the required contractual conditions, while the product/service to be provided by the collaborative $\mathrm{VO}$ is decomposed into a tree of subentities. 
2. To roughly plan the $\mathrm{VO}$, by selecting the collaboration modality of the VO to be created and activating the corresponding modeling tool (editors) and high-level planning.

The approach used consists in characterizing the $\mathrm{CO}$ in terms of product (definition of assemblies, components and even services according to an extendedproduct definition), project (activities, sub-activities and even products according to an extended-product definition), competencies required, and VO Rough Plan. This is done through an editor, with enhanced and innovative features for importing/exporting from both proprietary (like MS Project) and Open Source planning tools (i.e. GANTTProject). The characterized $\mathrm{CO}$ and the roughly planned $\mathrm{VO}$ are then passed to Partner Search and Suggestion and Negotiation wizard tools for selection of the partners and agreement negotiation.

The aim of the tool is to be a simple web-based application for enabling an easy-to-model approach for the VO planner. Thanks to a wizard like architecture, the modeling phase is relatively simple. By using a unique underlying Reference Model (XML schema), which unifies heterogeneous data sets and applications, the so called VO Model, an innovative aspect of the tool is the provision of a neutral data format and import/export functions for integrating legacy applications: ProJect Management Model (PJMM). Other innovative assets provided by the tool are the support to both the Resource-driven and Activity-driven management, and support to legacy applications. Fig. 5 shows one user interface for the module.

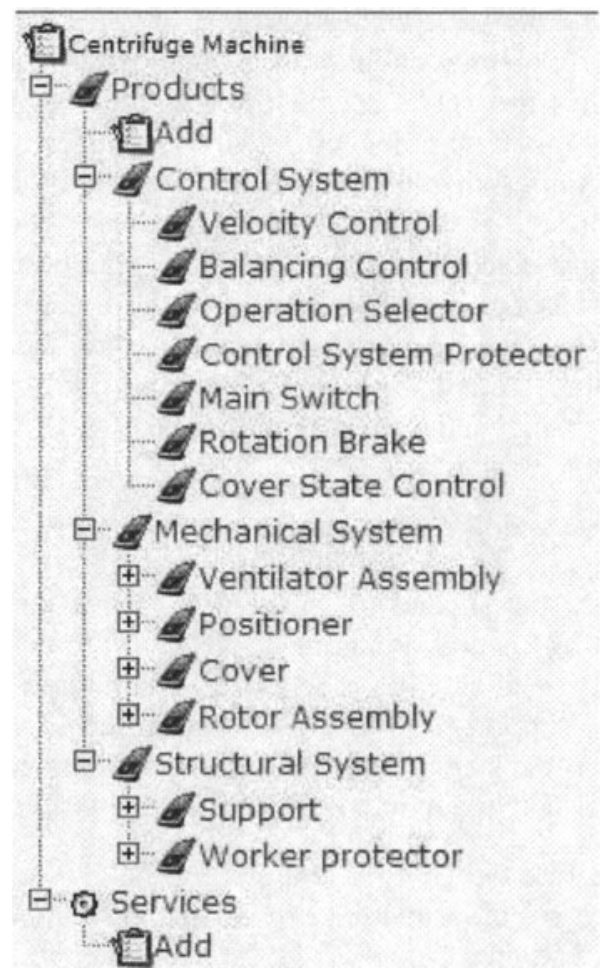

Figure 5 - CO Characterization and VO Rough Plan tool 


\section{PARTNERS SEARCH AND SUGGESTION}

The partner search and suggestion (PSS) process is decomposed in four functionalities, namely, Suggestion Criteria Identification, Partners Search, Generation of Suggested VOs, and Sensitivity Analysis. Fig. 6 presents the whole PSS process including both the information and control flows.

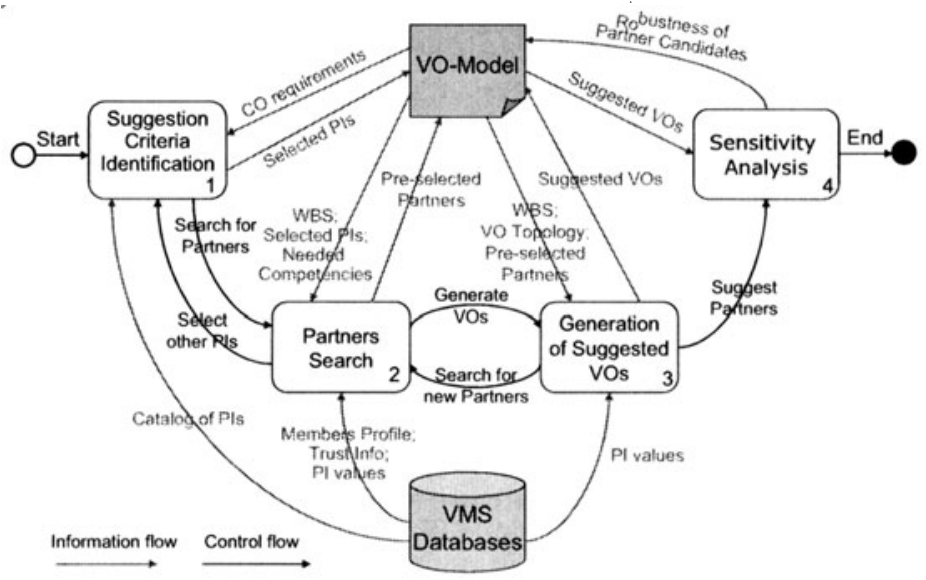

Figure 6 - Partners Search and Suggestion process

The suggestion criteria identification is the first stage in the PSS process. It comprises the selection of the most suitable performance indicators (PIs) used to measure organization's performance. In order to perform such process, it is assumed that the VBE has a well-defined set of PIs used to measure performance among those organizations that belong to it. The approach to identify the proper PIs is the utilization of information extraction techniques to annotate and indexing the information that describes the PIs. Using this indexed information combined with the VO's requirements, the entire set of PIs can be filtered and hence just the suitable ones are selected.

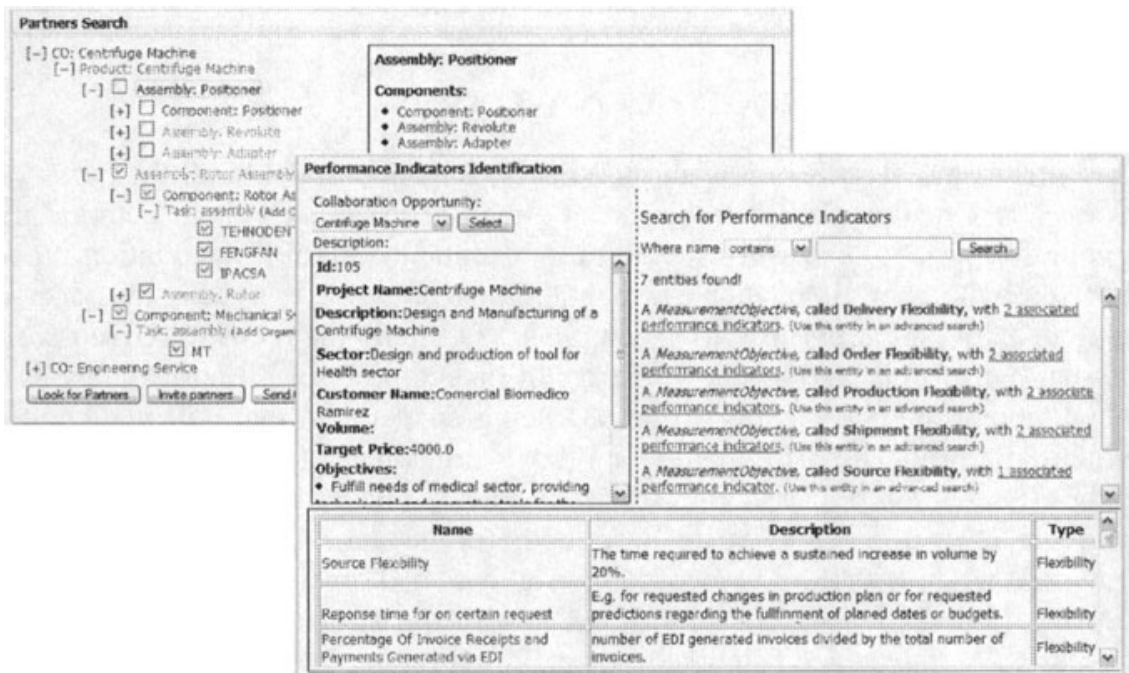

Figure 7 - Examples of interfaces of the PSS tool 
The partners search is performed using as main input the $\mathrm{CO}$ decomposition. This decomposition means the fragmentation, in elementary parts, of either a product or a service that must be produced or provided by a VO. The aim of partner search is to find the right organizations inside the VBE that can fit the required competencies assigned to the parts of the $\mathrm{CO}$ decomposition, as well as to fulfill the required partners' performance identified in the previous step.

The generation of suggested VOs identifies good VO configurations based on multi-criteria optimization models. Among others, the approach takes into account costs, risks, earlier performance, and even inter-organizational dependencies [10]. The generation of suggested VOs, combined with the sensitivity analysis functionality, allows the user to explore Pareto-efficient configurations and further modify and evaluate them. The VBE manager of a test case [9] was particularly satisfied with the model's capability of highlighting inter-organizational dependencies; for a decision maker it is difficult to intuitively see the total synergies of different configurations.

Table 1 presents an example of outcome provided by the generation of suggested VOs. The optimization routines identified five good configurations, on which the decision-maker can perform different kinds of sensitivity analysis.

Table 1 - Five suggested configurations and their performance on three criteria (all criteria are minimized).

\begin{tabular}{clllllllr}
\hline \# & $\begin{array}{l}\text { Bending } \\
\text { of pipes }\end{array}$ & $\begin{array}{l}\text { Engin- } \\
\text { eering }\end{array}$ & $\begin{array}{l}\text { Gear } \\
\text { milling }\end{array}$ & Grinding & $\begin{array}{l}\text { Project } \\
\text { mgmt }\end{array}$ & Cost & Risk & $\begin{array}{r}\text { Collab } \\
\text { oration }\end{array}$ \\
\hline 1 & SMA & Schuler & Okey & Brunner & VF AG & 131000 & 0,25 & 86 \\
2 & SMA & Schär & Okey & Brunner & VF AG & 133000 & 0,25 & 85 \\
3 & SMA & Schär & Okey & Brunner & Schär & 132000 & 0,75 & 73 \\
4 & SMA & AE\&P & Okey & Brunner & VF AG & 123000 & 0,75 & 83 \\
5 & SMA & AE\&P & Okey & Brunner & AE\&P & 122000 & 1,25 & 70 \\
\hline
\end{tabular}

For instance, Configurations 1 and 2 are less risky, whereas Configuration 5 is less expensive and the partners have better collaboration history. Moreover, SMA, Okey, and Brunner seem to be robust partner candidates, since they perform the same task in all the suggested configurations. The tool's novelty lies in its ability to account for risks and inter-organizational dependencies.

\section{AGREEMENT NEGOTIATION WIZARD}

The agreements' negotiation wizard (WizAN) runs in parallel to all the other tools of the VO Creation Framework, and is aimed at assisting human actors during negotiation processes towards the VO establishment. The full negotiation process involves a number of elementary negotiations in order to reach the necessary agreements with the purpose to accomplish VO internal agreement. Given so, the internal consortium agreement is the result or synthesis of all agreements established among the participants of the VO being created and that will regulate their collaboration [6]. The main inputs for WizAN are collected along the various steps of the VO creation process as illustrated in Figs. 1 and 2. These inputs shall come from the other tools previously described; for instance, the coFinder tool will provide WizAN with the CO identity, the "client" and other relevant data about the $\mathrm{CO}$; the COC-Plan tool provides WizAN with the structure of the process, the suggestion of the needed competencies, etc.; finally, the PSS tool provides WizAN 
with a suggested list of the most suitable configuration of partners to fulfill the $\mathrm{CO}$ requirements.

In order to properly answer to the identified requirements, WizAN comprises four main functionalities:

- CTR (Contract Templates Repository) that is a collection of agreement templates and clause templates to support the agreement creation;

- CE (Contract Editor) that uses the CTR and agreed negotiation topics to add new clauses to agreements;

- VNR (Virtual Negotiation Room) that is a virtual "place" where the negotiation participants can access the various negotiation topics and can "discuss" in order to reach the necessary agreements (Fig. 8);

- SAE (Support for Agreement Establishment) with facilities for agreement signing and notification of relevant parties, and repository/archive for its storage (a kind of e-notary).

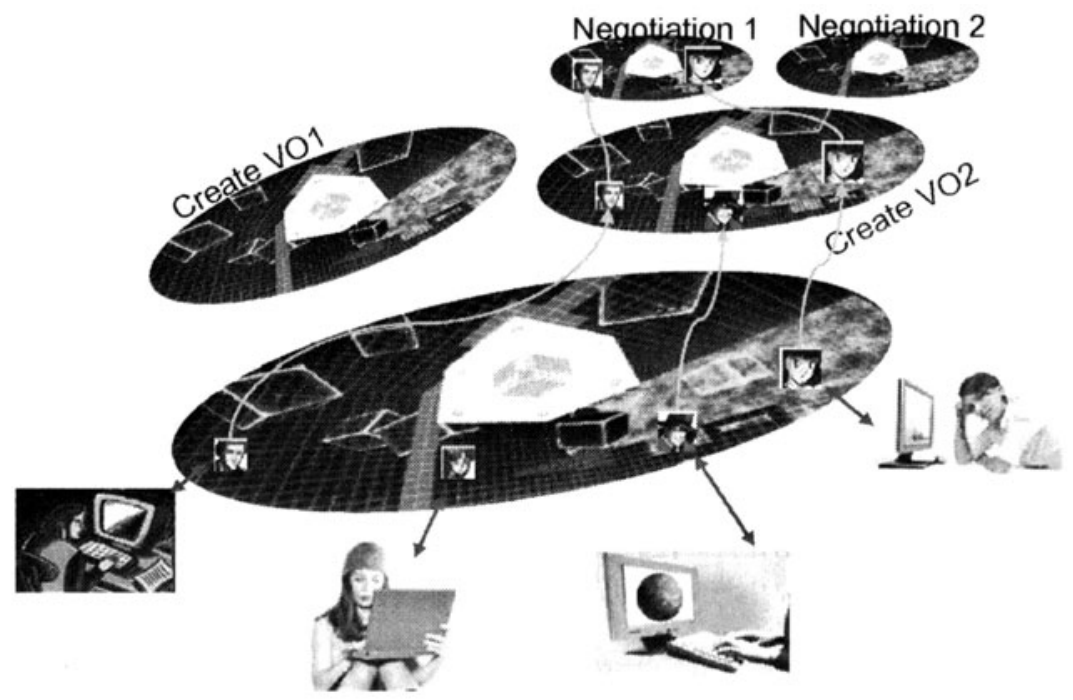

Figure 8 - Virtual negotiation rooms

There are two different situations where a negotiation might be required: (i) to select the best partners to compose the VO, and (ii) reaching agreement on the details of the VO. The WizAN is then intended to provide facilities for both, being the main result of it an agreement where all the related issues of the $\mathrm{VO}$ are covered.

Fig. 9 illustrates a rough flow of the negotiation during a VO creation process. Also in this figure, the relationship between WizAN and the other tools that are part of the VO Creation framework is depicted. 


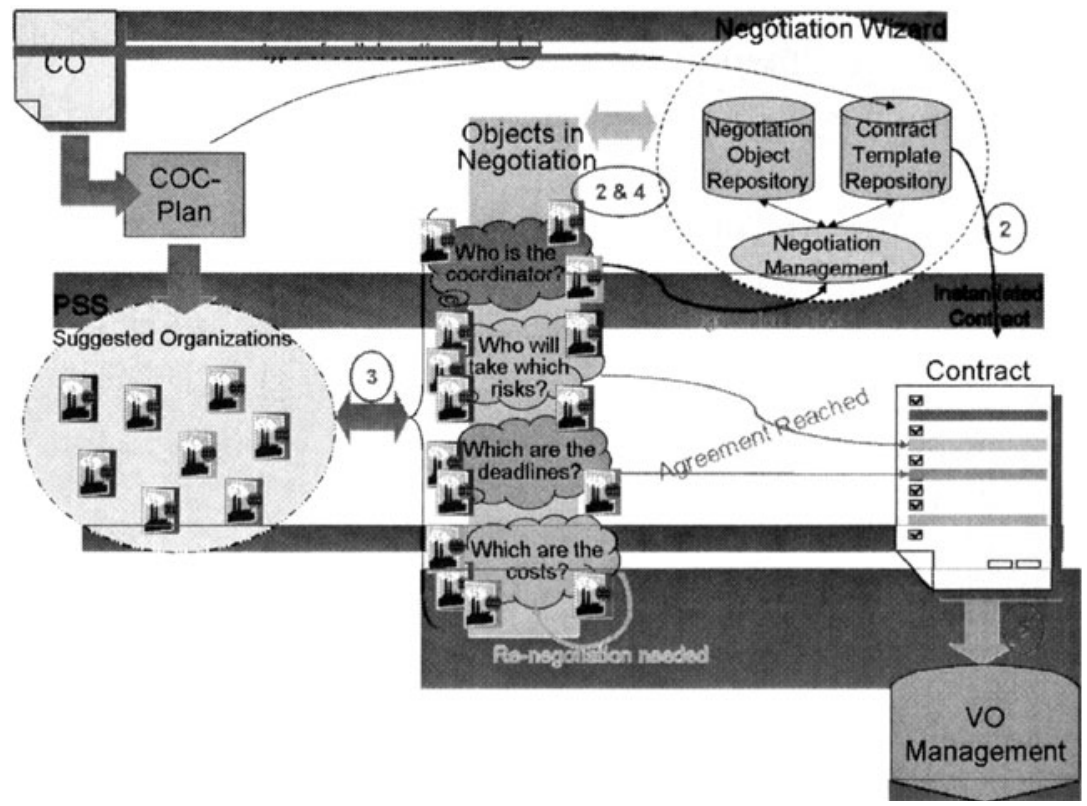

Figure 9 - WizAN usage scenario illustration.

1. First of all, it is necessary to know the type of collaboration that a specific $\mathrm{CO}$ requires. That kind of information is essential to conduct the rest of the negotiation;

2. With this information the WizAN can select the right template and also instantiate some general negotiation topics for that specific type of $\mathrm{CO}$;

3. In parallel with the negotiation, the partner search and suggestion process is performed. It is important to synchronize the partner search and selection according to the negotiation. For instance, when it is identified that is necessary to reach some agreements during the partner selection, this process shall be suspended and the execution should be handed over to WizAN until the agreement is reached;

4. After finishing the partners search and suggestion process, another bunch of negotiation steps should start. At this point, it is necessary to reach agreements concerning rights, duties, responsibilities, etc.;

5. Compilation of those agreed negotiation topics in order do build the so called "Contract" or consortium agreement. At this point, tools to support the collaborative writing of documents, as well as e-notary functions can be used;

6. Although all these tools suggest certain configurations for the VO creation, it is important to remark that final decisions are always subject of human interaction.

In Fig. 10 some of the developed interfaces of the WizAN tool are illustrated. 


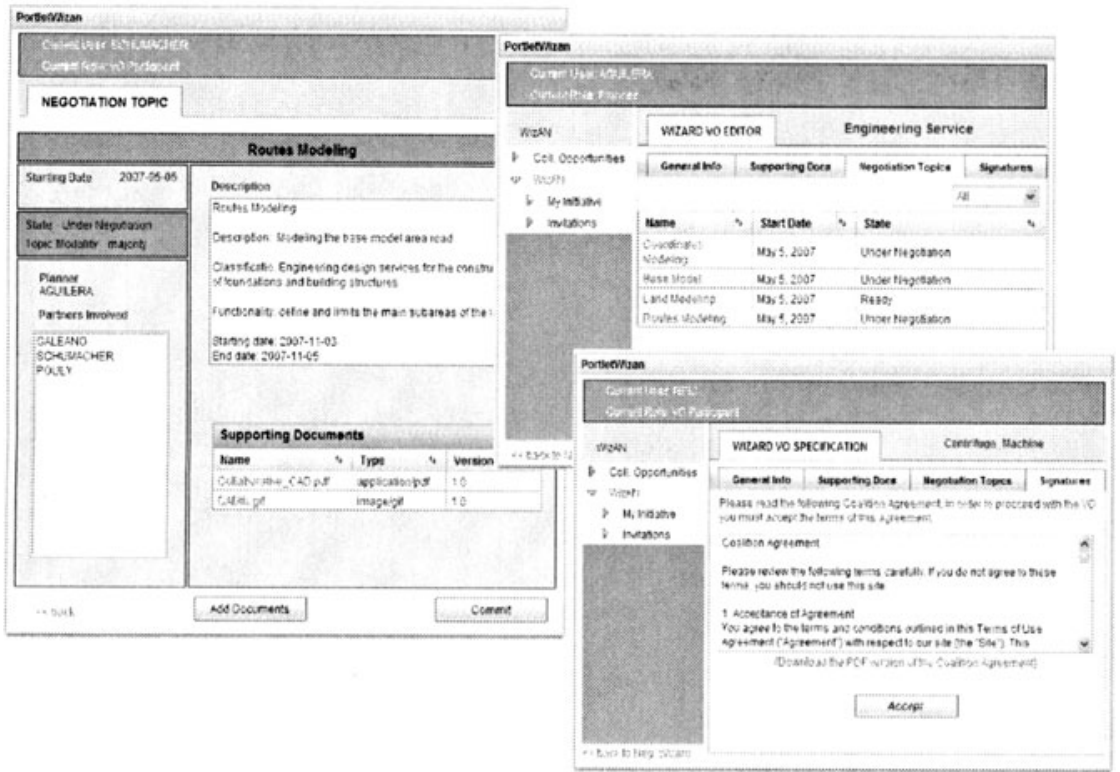

Figure 10 - Example of WizAN Interfaces

\section{CONCLUSIONS}

The time and amount of resources consumed during the VO creation process whenever a business/collaboration opportunity is acquired, give a good indication of the level of agility of a collaborative network. The effectiveness of this process mainly depends on the availability of adequate information about potential partners and their level of preparedness for VO involvement. The existence of a VO breeding environment facilitates the fulfillment of these requirements and thus enables truly dynamic VOs.

The ECOLEAD approach to VO creation is developed under such assumption, and proposes a detailed process covering all required steps from the identification of the collaboration opportunity till the actual launching of the VO that will exploit that opportunity. A set of tools are proposed to support an iterative decisionmaking process in which the final decisions are made by the broker/VO planner.

Acknowledgements. This work was supported, in part, be the European Commission through the ECOLEAD project. The authors also thank the contribution of their partners.

\section{REFERENCES}

1. Afsarmanesh, H., \& Camarinha-Matos, L. M. (2000). Future smart organizations: A virtual tourism enterprise. Proc. of WISE 2000 - Ist ACM/IEEE International Conference on Web Information Systems Engineering, Hong Kong.

2. Afsarmanesh, H., L. M. Camarinha-Matos (2005). A framework for management of virtual organization breeding environments. In: Collaborative Networks and their Breeding Environments, pp. $35-48$, Springer, Boston.

3. Angelov, S., P. Grefen (2003). The $4 \mathrm{~W}$ framework for B2B e-contracting. Int. J. Networking and Virtual Organizations, 2, No. 1, 78-97. 
4. Boon, B. H., Sierksma, G. (2003). Team formation: Matching quality supply and quality demand, European Journal of Operational Research, vol. 148, pp. 277-292.

5. Camarinha-Matos, L. M., H. Afsarmanesh (2003). Elements of a base VE infrastructure. Computers in Industry, 51, Issue 2, 139-163.

6. Camarinha-Matos, L. M., Oliveira, A. I. (2006). Contract Negotiation Wizard for VO Creation. Paper presented at the 3rd Int. CIRP Conference on Digital Enterprise Technology, Setúbal.

7. Camarinha-Matos, L. M., Silveri, I., Afsarmanesh, H., \& Oliveira, A. I. (2005). Towards a Framework for Creation of Dynamic Virtual Organizations. In Collaborative Networks and theirs Breeding Environments (pp. 69-80): Springer.

8. Ip,W. H., Yung, K. L.,Wang, D. (2004). A branch and bound algorithm for sub-contractor selection in agile manufacturing environment, International Journal of Production Economics, vol. 87, no. 2, pp. 195-205.

9. Jarimo, T., I. Salkari, S. Bollhalter, (2006). Partner selection with network interdependencies: An application. In: Network-Centric Collaboration and Supporting Frameworks, Springer, Boston.

10. Jarimo, T., U. Pulkkinen (2005). A multi-criteria mathematical programming model for agile virtual organization creation. In: Collaborative Networks and their Breeding Environments, Springer, Boston.

11. Kaihara, T. (1999). Supply chain management based on market mechanism in virtual enterprise. In: Infrastructures for Virtual Enterprises - Networking Industrial Enterprises Kluwer Academic Publishers, Boston.

12. Kaihara, T., S. Fujii, S. (2006). Game theoretic negotiation strategy for virtual enterprise with multiagent systems. In: Network-centric Collaboration and Supporting Frameworks, Springer, Boston.

13. Ko, C. S., Kim, T., Hwang, H. (2001). External partner selection using tabu search heuristics in distributed manufacturing, International Journal of Production Research, vol. 39, no. 17, pp. 3959-3974.

14. Li, Y., B. Q. Huang, W. H. Liu, C. Wu, H. M. Gou (2000). Multi-agent system for partner selection of virtual enterprises. In: Proceedings of 16th IFIP World Computer Congress 2000, Vol. ITBM, Publishing House of Electronics Industry, Beijing.

15. Meyer, J. J., R. J. Wieringa (1993). Deontic Logic in Computer Science: Normative System Specification. John Wiley and Sons, 1993.

16. Mikhailov, L. (2002). Fuzzy analytical approach to partnership selection in formation of virtual enterprises, Omega, vol. 30, pp. 393-401.

17. Rabelo, R.J., L. M. Camarinha-Matos (1994). Negotiation in Multi-Agent based dynamic scheduling. Int. Journal on Robotics and CIM, 11, N. 4, 303-309.

18. Rabelo, R. J., L. M. Camarinha-Matos, R. V. Vallejos (2000). Agent-based Brokerage for Virtual Enterprise Creation in the Moulds Industry, E-business and Virtual Enterprises (pp. 281-290): Kluwer Academic Publishers.

19. Rocha, A., E. Oliveira (1999). An electronic market architecture for the formation of virtual enterprises. In: Infrastructures for Virtual Enterprises - Networking Industrial Enterprises, Kluwer Academic Publishers, Boston.

20. Sha, D. Y., Che, Z. H. (2005). Virtual integration with a multi-criteria partner selection model for the multi-echelon manufacturing system, The International Journal of Advanced Manufacturing Technology, vol. 25, no. 7-8, pp. 793-802.

21. Shen, W., \& Norrie, D. H. (1998). An agent-based approach for distributed manufacturing and supply chain management. In Digital Communications Era of the 21 st Century. Boston: Kluwer.

22. Wu, N., Su, P. (2005). "Selection of partners in virtual enterprise paradigm," Robotics and Computer-Integrated Manufacturing, vol. 21, pp. 119 131. 